SISTEMA
ELETRONIICO
DE REVISTAS
SER I UfPR

\title{
O Antropoceno e a mudança climática: a percepção e a consciência dos brasileiros segundo a pesquisa IBOPE
}

\section{Anthropocene and climate change: the perception and awareness of Brazilians according to the IBOPE survey}

\author{
Geraldo Estevo PINTO ${ }^{1}$, André PIRES ${ }^{1 *}$, Marcos Ricardo Rosa GEORGES ${ }^{1}$ \\ ${ }^{1}$ Pontifícia Universidade Católica de Campinas (PUC-Campinas), Campinas, São Paulo, Brasil. \\ *E-mail de contato: anpires@puc-campinas.edu.br
}

Artigo recebido em 4 de julho de 2019, versão final aceita em 25 de março de 2020, publicado em 30 de julho de 2020.

RESUMO: Um nó górdio ata a atual era denominada Antropoceno à forma de pensar a terra e a sociedade que nela habita. A cultura moderna se edificou compreendendo o ser humano como o senhor e o dono de todas as coisas. Logo, os sinais de alertas emitidos pela natureza e a sua não compreensão crítica por parte da humanidade transformaram o problema em crise profunda, observável no aquecimento global e na mudança climática. Em 20 anos, 4,1 bilhões de pessoas foram atingidas por este último fenômeno. $\mathrm{O}$ conhecimento da percepção e do nível de consciência dos brasileiros com relação à transformação da terra e com respeito à ação humana neste processo é indispensável para a formulação correta do problema e a busca de soluções. A partir de uma pesquisa de opinião pública realizada em 2011, o estudo tem por objetivo analisar os dados referentes à percepção dos brasileiros com respeito ao fenômeno do aquecimento global e da mudança climática e, ainda, identificar a sua consciência com relação à ação humana neste processo. Além da revisão bibliográfica, é utilizada como fonte secundária a Pesquisa IBOPE publicada em 2012. Não são identificadas posições negacionistas ou obstáculos psicológicos quanto à percepção da mudança climática, entretanto, não é possível identificar perspectivas de reação às formas de pensar que têm colocado o ser humano e seu modelo de desenvolvimento em rota de colisão com a natureza e o planeta.

Palavras-chave: mudança climática; aquecimento global; antropoceno; percepção ambiental; Brasil.

ABSTRACT: A Gordian knot ties the present age called Anthropocene to the way of thinking about the land and the society that inhabits it. Modern culture was built by understanding the human being as the master and owner of all things. Therefore, the warning signals issued by nature and their lack of critical understanding on the part of humanity 
turned the problem into a deep crisis, observable in global warming and climate change. In 20 years, 4.1 billion people have been hit by this latest phenomenon. The knowledge of the perception and level of consciousness of Brazilians in relation to the transformation of the land and with respect to human action in this process is indispensable for the correct formulation of the problem and the search for solutions. From a public opinion survey conducted in 2011 the study aims to analyze the data referring to the perception of Brazilians regarding the phenomenon of global warming and climate change and also identify their consciousness with regard to human action in this process. In addition to the bibliographic review, a secondary source is used, the IBOPE Research published in 2012. No negationist positions or psychological obstacles are identified regarding the perception of climate change, however it is not possible to identify perspectives of reaction to the ways of thinking that have placed the human being and his development model on a collision course with nature and the planet.

Keywords: climate change; global warming; anthropocene; environmental perception; Brazil.

\section{Introdução}

Um nó górdio ata a atual era denominada Antropoceno à forma de pensar a terra e sociedade que nela habita. A proposição de uma nova era biogeológica pode ser compreendida como uma realidade no espaço e no tempo, na qual os seres humanos, a partir de sua ação no planeta, constatam que impactaram tragicamente o espaço da sua habitação como também a escala do tempo geológica. Em 2002, o químico holandês Paul Crutzen (2002) sintetizou e caracterizou este momento histórico:

“Parece apropriado atribuir o termo 'Antropoceno' ao presente, de muitas maneiras dominado pelo homem, como época geológica, completando o Holoceno- o período quente dos últimos 10-12 milênios. Pode-se dizer que o Antropoceno começou na última parte do século XVIII, quando as análises do ar preso no gelo polar mostraram o início de crescentes concentrações globais de dióxido de carbono e metano". (Crutzen, 2002, tradução nossa).

O Antropoceno não é sinônimo de mudança climática, entretanto, o clima e o tempo são as mais evidentes manifestações de todos os processos do sistema terra e das recentes e intensivas transformações, não observáveis anteriormente na história, segundo Graedel \& Crutzen (1997). De acordo com Marques Filho (2016, p. 309), existe um forte consenso entre os cientistas quanto ao impacto das emissões dos gases de efeito estufa e a consequente mudança climática e destaca que 38 academias científicas, a partir do ano de 2001, divulgaram relatórios oficiais "confirmando o caráter preponderantemente antrópico das mudanças climáticas". Portanto, a origem e a fonte destas alterações são identificadas. As consequências são palpáveis, pois de 1995 a 2015, segundo órgão da Organização das Nações Unidas, 4,1 bilhões de pessoas foram afetadas por desastres ambientais relacionados ao aquecimento global (UNISDR \& CRED, 2015).

$\mathrm{Na}$ clássica formulação da modernidade, o ser humano é o senhor e dono da natureza (Boff, 2015). Este pensamento fortaleceu o antropocentrismo como forma de elaborar os problemas e de buscar soluções técnicas'. Para Santos (2001), ocorreu uma redução da emancipação moderna à

\footnotetext{
${ }^{1}$ Para Seligman-Silva (2019), a história da técnica se confunde com a história da humanidade. Ao analisar as catástrofes tecnológicas tendo como cenário o rompimento das barragens de Mariana em novembro de 2015 e de Brumadinho em janeiro de 2019, recorre ao conceito da
} 
razão instrumental das ciências e uma redução da regulação moderna ao princípio do mercado, pois o conhecimento humano e seus instrumentos tecnológicos são postos em movimento por interesses alheios à emancipação humana (Habermas, 1987).

A crise do paradigma moderno do conhecimento (Santos, 2001), a mediação dos meios de comunicação e o impacto sobre o próprio meio ambiente e hábitat humano atingem a percepção do homem sobre si e sobre o seu ambiente. Deste modo, é necessário pesquisar a percepção da população brasileira quanto ao aquecimento global, o entendimento da sua importância, as causas e a responsabilidade por este fenômeno, objetivando as formulações de políticas ambientais e a educação ambiental.

Nesta perspectiva, a partir de uma pesquisa de opinião pública realizada em dezembro de 2011 (CNI \& IBOPE, 2012), o presente estudo tem por objetivo analisar os dados referentes à percepção dos brasileiros em relação ao fenômeno do aquecimento global e identificar a sua consciência em relação à ação humana neste processo. Para isto, utiliza-se uma fonte secundária, a pesquisa do IBOPE (CNI \& IBOPE, 2012) e, a partir da revisão bibliográfica, os dados serão analisados e interpretados. O resultado da pesquisa publicada em 2012 pela Confederação Nacional da Indústria (CNI) é a última publicada em âmbito nacional referente aos temas, de forma conjunta, do meio ambiente, da seleção do lixo e reciclagem, mudanças climáticas e aquecimento global. Estes dados serão cotejados com pesquisas recentes do Datafolha (Garcia, 2019) e Ipsos (Ipsos Global Adviser, 2019). Se, por um lado, as mudanças tecnológicas, os impactos sobre o meio ambiente e a vida social manifestam-se de forma dinâmica e célere, por outro, as percepções enquanto tendências são fenômenos mais consistentes e internos. Para o estudioso deste fenômeno, Zygmund Bauman (2009, p. 7), a vida, ou a modernidade líquida, "é uma sociedade em que as condições sob as quais agem seus membros mudam num tempo mais curto do que aquele necessário para a consolidação, em hábitos e rotinas, das formas de agir" que, por estarem autocentradas, possuem um fluxo mais ameno ${ }^{2}$.

Os resultados da pesquisa sugerem que não são evidenciadas visões negacionistas ou mecanismos psicológicos capazes de impedir o conhecimento e a percepção dos problemas aludidos, por outro lado, o discurso estabelecido não conduz ao aprofundamento da consciência de modo crítico, capaz de questionar a ação antrópica, o seu modo de produção, consumo e o seu protagonismo gerador da crise ambiental e planetária.

O artigo está organizado em cinco seções, incluída a introdução. Na segunda, são analisados os conceitos do Antropoceno e da mudança climática,

\footnotetext{
"primeira técnica", de Walter Benjamin, o qual está fundado no conceito de progresso, cuja finalidade, na leitura de Seligman-Silva (2019, p. 1), é "o sacrifício da vida, a destruição, o controle e a dominação da natureza que leva à sua asfixia”.

2 Bauman (2009) refere-se à dinâmica do autorreferenciamento, a qual não se altera na mesma velocidade que a sociedade, pois é voltada para o interior do indivíduo, e afirma: "Se a vida líquida estimula algum interesse pela transformação social, a reforma defendida tem como principal objetivo empurrar a sociedade em direção à rendição de todas as suas pretensões a um valor próprio, com exceção do valor de uma força policial para preservar a segurança dos "eus" que se autorreformam (...). Até a recente preocupação com o meio ambiente deve a sua popularidade à percepção de um vínculo entre o uso predatório dos espaços planetários e as ameaças ao fluxo suave das atividades autocentradas da vida líquida.” (Bauman, 2009, p. 19-20, grifo nosso).
} 
a origem destes fenômenos e as respostas da ciência e da sociedade. Na terceira seção é apresentada a metodologia da pesquisa e, em seguida, são analisados os dados quanto à percepção dos brasileiros sobre aquecimento global e a sua consciência sobre a origem e a fonte deste processo. A quinta seção corresponde às considerações finais.

\section{Antropoceno e mudança climática: faces de uma crise antropocêntrica.}

A revista do The New York Times de agosto de 2018 foi reservada a um único tema: "Losing Earth: The Decade We Almost Stopped Climate Change" (Perdendo a Terra: a década que quase paramos a mudança climática) (Rich, 2018, p. 1, tradução nossa). A reportagem do jornalista Nathaniel Rich é um alerta trágico sobre a crise ambiental, e o foco principal está nos anos de 1979 a 1989 quando, segundo o jornalista, "nós tivemos uma excelente oportunidade para resolver a crise climática" (2018, p. 1, tradução nossa). Por parte da opinião pública havia a aceitação das pesquisas científicas que indicavam os danos ao meio ambiente, e as indústrias de combustíveis fósseis ainda não atuavam na desinformação. A questão não havia sido partidarizada de acordo com o contexto norte-americano, ou seja, o tema era discutido por republicanos e democratas, e a conclusão do jorna- lista é a seguinte: "os obstáculos que nós culpamos por nossa atual inação ainda tinha que emergir. Quase nada ficou em nosso caminho- nada, exceto nós mesmos" (Rich, 2018, p. 1, tradução nossa).

A reportagem compreende o "nós" de modo etnocêntrico, os atores e os agentes norte-americanos, em contrapartida, o fracasso por "perder a Terra" é tributado à natureza humana, ou seja, a crença da excepcionalidade humana e daquele exato contexto histórico norte-americano capaz de "salvar a Terra". Ignora o texto ainda que a referida década foi marcada pelo avanço do neoliberalismo no mundo globalizado e pela formulação do Consenso de Washington, em 1989 (Sachs, 2008) $)^{3}$. Frente à trágica perda da Terra, a revista dominical focaliza a natureza humana e ignora a natureza do capitalismo, ou seja, por outras vias mantém a ilusão de um capitalismo sustentável e do crescimento ilimitado do excedente (Marques Filho, 2016).

Há um consenso na ciência de que o planeta Terra tem passado por alterações biogeoquímicas e transformações da paisagem de modo abrupto em um período curto da história. Isto tem consequências éticas frente às gerações do presente e do futuro e responsabilização para com o futuro de todas as espécies do planeta (Boff, 2015). Este fenômeno comporta consequências epistemológicas de forma contundente, acentua Ignacy Sachs (2008, p. 49): "O paradigma básico do pensamento científico,

\footnotetext{
${ }^{3}$ De acordo com Sachs (2008, p. 27-28), “o Consenso de Washington atuou como uma contrarreforma direcionada ao capitalismo reformado, que atingiu sua maturidade após a Segunda Guerra Mundial, inspirado nos escritos de Keynes e Beveridge e nas experiências do New Deal americano". O termo "Consenso de Washington", segundo Portela Filho (1994, p. 1), "foi usado por John Williamson para descrever o conjunto de propostas econômicas defendidas pelos políticos e tecnocratas residentes na capital americana. Ele definiu o consenso de forma ampla, abrangendo tanto o Washington político, onde residem congressistas e membros da administração federal, como também o Washington tecnocrático das instituições financeiras internacionais e do Federal Reserve Board”. Em um estudo sobre o ajustamento da América Latina, John Williamson (1990, apud Portela Filho, 1994) listou 10 tipos de políticas e reformas econômicas que foram objeto de consenso entre os doutrinadores de Washington durante os anos 1980.
} 
herdeiro de Bacon e Descartes, chegou ao fim no que concerne à pretensão de dominar a natureza". De acordo com Boaventura dos Santos, o modelo global de racionalidade científica consolidou:

A redução da emancipação moderna à racionalidade cognitiva instrumental das ciências e a redução da regulação moderna ao princípio do mercado, incentivados pela conversão da ciência na principal força produtiva, constituem as condições determinantes do processo histórico que levou a emancipação moderna a render-se à regulação moderna (Santos, 2001, p. 57).

Georgescu-Roegen (2012) vai buscar nos fundamentos lógicos da ciência econômica clássica, fundamentados nos conceitos da física mecânica, a explicação para a transformação, de forma irreversível, por meio da entropia, dos recursos naturais finitos em mercadoria. Ao propor, ainda em 1979, o decrescimento econômico, foi marginalizado do meio científico e econômico (Veiga, 2010), sem abdicar da sua contestação a "todo fator que possa limitar a vida da humanidade" (Georgescu-Roegen, 2012, p. 95). Esta mesma postura ética é compartilhada por Jürgen Habermas (1987, p. 347), para o qual "a universalidade dos interesses com o conhecimento significa que as condições de reprodução da espécie humana ou da forma de vida sociocultural impõe-se, como tais, na área do objeto". Habermas (1987) propõe o resgate da epistemologia, reduzida à metodologia pelo positivismo, e sugere a união do conhecimento com o interesse emancipatório. Georgescu-Roegen e Habermas presenciaram a guerra mundial, os inúmeros testes nucleares e os primeiros sintomas significativos da deterioração da natureza.
Compreendendo o problema do conhecimento e da ação humana diante da natureza, sob a perspectiva holística, Leonardo Boff resume:

\begin{abstract}
A Terra deixou de ser a Magna Mater dos antigos, a $\mathrm{Pa}$ chamama dos andinos e a Gaia dos contemporâneos, algo vivo e gerador de vida, para ser transformada numa coisa inerte (res extensa de Descartes), numa vitrine de recursos colocados à disposição da voracidade ilimitada dos seres humanos. Clássica é a formulação de René Descartes: o ser humano é o "maître et possesseur" da natureza, isto é, ele é o senhor e dono da natureza. Ele pode fazer dela o que bem entender. E o fez (Boff, 2017, p.1, tradução nossa).
\end{abstract}

A modernidade pode ser interpretada como a era do antropocentrismo e, ao mesmo tempo, como a era do poder imensurável do homem sobre o meio ambiente, portador inclusive da capacidade de sua autoextinção. Este paradoxo vai ser compreendido dentro de outro conceito mais amplo analisado adiante, o Antropoceno. Desfaz a suposição da terra como puro objeto de conhecimento, imprimido pela separação do homem da natureza. A redução e a disjunção como caraterística do paradigma simplificador e mutilador da realidade entra em crise cultural (Morin, 2011).

Para Marques Filho (2016), a formulação do conceito Antropoceno é pluriautoral, abrangendo o período de 1972 a 2002. Em parte, este percurso é descrito na publicação do The International Geosphere-Biosphere Programme (IGBP), no ano de 2000, que terminou por consolidar o termo através do artigo intitulado The "Antropocene", assinados por Crutzen \& Stoermer (2000). O artigo científico compreende que o conceito foi emergindo lentamente na ciência, a partir da publicação de G.P. 
Marsh, em 1864, intitulado "The Earth as Modified by Human Action", dos comentários de Stoppani, em 1873, acentuando a grande força da atividade humana na terra, designando-a como era Antropozoica e, a partir do geologista russo Vernadsky, que em 1926 ressaltava o poder da espécie humana como parte da biosfera. Por fim, relata o conceito de Noosfera, que enfatiza o poder da razão e da técnica na formação do futuro e do meio ambiente, elaborado por Pe. Teilhard de Chardin e Le Roy em 1924. Deste modo, Crutzen \& Stoermer propõem a denominação de uma nova época geológica e assim definem este momento histórico de transformação da natureza:

Considerando esses e vários outros crescentes impactos das atividades humanas na terra e na atmosfera, e em todas as escalas, inclusive global, parece-nos mais do que apropriado enfatizar o papel central da humanidade na geologia e na ecologia propondo o uso do termo "antropoceno" para a época geológica atual. Os impactos das atividades humanas atuais vão continuar por longos períodos. Segundo um estudo de Berger \& Loutre, devido às emissões de $\mathrm{CO} 2$ antropogênicas, o clima pode se afastar significativamente de seu comportamento natural ao longo dos próximos 50.000 anos (Crutzen \& Stoermer, 2000, p. 17, tradução nossa).

A proposição de uma nova época geológica foi formalizada em 2009, na Comissão Internacional de Estratigrafia e, para tanto, foi formado um grupo de trabalho e pesquisa, cujo maior desafio é integrar cientificamente os dados sobre as ações humanas conhecidas na história com as evidências das pes- quisas biogeológicas (SQS, 2009). O conceito de Antropoceno abarca, portanto, a convergência de uma sequência de manifestações compreendidas pela ciência como crises ambientais. Steffen et al. (2015) identificam que, a partir da segunda metade do século XX, ocorre uma aceleração, sem precedentes na história, verificável nos sistemas socioeconômicos e biofísico da Terra. Estas mudanças fundamentais nos indicadores do Sistema Terra, a partir do que denomina "A Grande Aceleração", estão para além do intervalo de variabilidade biogeoquímicas ocorridas no Holoceno.

A proposição do conceito de Antropoceno não está isenta de contestações. Veiga (2019) sustenta que a noção de "Sistema Terra" é um limitador e conduz ao modelo de compreensão sistêmica de todos os fatores da dinâmica da Terra e se confronta com o pensamento complexo ${ }^{4}$, dando origem a ambiguidades como aquela do conceito de desenvolvimento sustentável, a primeira utopia do Antropoceno.

Entretanto, depreende-se deste conceito que a dinâmica da natureza tem sido impactada pela atividade humana, provocando desequilíbrios químicos, biológicos e geológicos no planeta, sendo que alguns destes efeitos permanecerão por milênios. Sob esta ótica, Marques Filho (2016, p. 459) analisa que o Antropoceno é "a revelação da impotência de nossa potência", revelação da incapacidade de produzirmos e consumirmos economicamente dentro dos limites ecossistêmicos e, ao mesmo tempo, incapacidade de nos "libertarmos do paradigma quantitativo, compulsivamente expansivo

\footnotetext{
${ }^{4}$ De acordo com Veiga (2019, p. 119), futuros avanços do pensamento complexo "poderão dirimir dúvidas sobre as conexões entre o processo civilizador, a natureza humana, a vida em geral e a realidade inorgânica do planeta", dinâmicas coevolutivas do Sistema Terra.
} 
e antropocêntrico da economia capitalista". Esta relação é totalmente ignorada na matéria mencionada acima, do The New York Times, que desloca o problema real para o âmbito da ontologia humana (Rich, 2018).

O conceito de Antropoceno não é sinônimo de mudança climática, no entanto, abarca a convergência de uma sequência de manifestações compreendidas pela ciência como crises ambientais. Um dos sintomas desta crise, como já destacado, é a mudança climática (SQS, 2009; Gardel \& Crutzen, 1997), que, associada ao fenômeno do aquecimento global, ganhou foco e espaço nos meios de comunicação, principalmente a partir da Conferência das Nações Unidas sobre o Meio Ambiente e Desenvolvimento, realizada entre os dias 3 e 14 de junho de 1992, na cidade do Rio de Janeiro (Barbieri, 2008). As convenções internacionais passaram, portanto, a desempenhar um papel de protagonismo na agenda das questões ambientais.

As primeiras evidências sobre as alterações de origem antrópica no clima da terra começaram a surgir na década de 1960, a partir da concentração de dióxido de carbono $\left(\mathrm{CO}_{2}\right)$ na atmosfera, um dos gases responsáveis pelo efeito estufa (Marques Filho, 2016; Graedel \& Crutzen, 1997). Este fato motivou, em 1979, a realização da I Conferência Mundial sobre o Clima em Genebra, que confirmou as evidências das atividades antrópicas sobre o clima (IPEA, 2010). Em 1988, foi criado o Painel Intergovernamental sobre Mudanças do Clima- Intergovernmental Panel on Climate Change (IPCC, 1988), por iniciativa do Programa das Nações Unidas para o Meio Ambiente (Pnuma) e da Organização Meteorológica Mundial (OMM). O primeiro relatório do IPCC concluiu que as atividades antrópicas que emitem gases de efeito estufa estavam aumentando de forma substancial, com a média de elevação da temperatura em $0,3^{\circ} \mathrm{C}$ por década (IPCC, 1988).

Nessa conjuntura, considerando os riscos provocados pelas mudanças do clima, a Organização das Nações Unidas (ONU) criou a Convenção-Quadro das Nações Unidas para Mudanças do Clima (United Nations Framework Convention on Climate Change-UNFCCC), em 1990. Durante a realização da Cúpula da Terra, em 1992, no Rio de Janeiro, foram abertas as adesões à convenção internacional com a finalidade de estabilizar as emissões e discutir a responsabilidade comum e diferenciada entre os Estados membros (IPEA, 2010). Em decorrência, foi constituído o órgão supremo da convenção, a Conferência das Partes (COP), com o objetivo de estabelecer metas, e não somente medidas políticas. As reuniões ocorrem anualmente desde 1995, em diferentes cidades e países (Aguiar, 2012; Souza \& Corazza, 2017).

A COP-3, realizada em Quioto no ano de 1997, decidiu por consenso a adoção de um protocolo oficial. O Protocolo de Quioto representou uma tentativa de alcançar o objetivo da convenção e definiu, dessa forma, metas quantitativas para os países industrializados, em lugar de medidas e políticas gerais (Souza \& Corazza, 2017). O relatório de avaliação do IPCC 2007 ampliou a compreensão do fenômeno da mudança climática, com abordagens científicas sobre os seus efeitos, as suas causas e as projeções futuras. Além dos temas das emissões dos gases efeito estufa e do aquecimento global, integraram a temática as questões relativas à matriz energética, ao impacto da economia e tecnologia, ao desmatamento, a perda da biodiversidade e aos meios de transporte (IPCC, 2007). O Acordo de Paris $\left(21^{\circ} \mathrm{COP}\right)$, realizado em 2015 , determinou que os 195 países signatários se esforçassem para 
conter o aquecimento global a menos de $2^{\circ} \mathrm{C}$ até o final do século. O IPCC de 2018, após o estudo de 6.000 publicações científicas, sugeriu diminuir esta meta para $1,5^{\circ} \mathrm{C}$ (IPCC, 2018; Normile, 2018), proposta apresentada na $23^{\circ} \mathrm{COP}$ na Coreia do Sul, em decorrência da pressão das nações insulares, sob o risco de aumento do nível do mar. Normile, num texto publicado na revista Science Magazine, relata a advertência dos cientistas:

(...) ultrapassar os $1,5^{\circ} \mathrm{C}$ será desastroso. Por exemplo, com 1,5 graus de aquecimento, projeta-se que o nível do mar aumente 26 a 77 centímetros até 2100 ; indo para $2^{\circ} \mathrm{C}$, acrescenta mais 10 centímetros, o que afetaria mais 10 milhões de pessoas que vivem em regiões costeiras. Com 2 graus de aquecimento, plantas, insetos, animais e vida marinha serão empurrados mais longe das atuais faixas geográficas. Estima-se que os recifes de corais diminuam de $70 \%$ a $90 \%$ a $1,5^{\circ} \mathrm{C}$, mas a 2 graus, $99 \%$ dos recifes seriam devastados. Haveria maior incidência de tempestades, inundações e seca (Normile, 2018, tradução nossa).

Ao analisar a atuação dos organismos internacionais, Souza \& Corazza (2017) observam que a Conferência das Partes de Paris, em 2015, representou uma mudança na abordagem, partindo de "baixo", envolvendo novas coalizões e lideranças mundiais. Anthony Giddens (2010) reconhece os impasses em nível internacional e propõe uma reestruturação dos organismos para que sejam capazes de abarcar o assunto da complexidade global. Ao sugerir a política da mudança climática com base em Estados asseguradores, capazes de convergências econômicas e políticas, propõe a configuração de três contextos internacionais: dos processos decisórios da economia, assumindo prioritariamente a pauta da energia renovável; da política, procurando desenvolver ações antecipatórias e, por fim, da geopolítica mundial. Para o pesquisador, as alterações no clima trazem implicações geopolíticas (Giddens, 2010). Nesta perspectiva, Martinez Alier (2012) alerta para o confronto de interesses, quando o impacto do desenvolvimento econômico gera "conflitos ecológicos distributivos", por meio do deslocamento geográfico das fontes de recursos e das áreas de descarte de resíduos. Deste modo, há um movimento avançando sobre novas fronteiras, indo dos países ricos para os países pobres. Outra abordagem relacionada à questão do clima no âmbito intergovernamental refere-se ao comércio internacional. A ordem econômica internacional enquadra os países pobres e em desenvolvimento na função de fornecedores de commodities e de matéria-prima de alta intensidade no uso de recursos naturais e de energia, cabendo a industrialização apenas de produtos de baixa intensidade tecnológica (IPEA, 2010). Portanto, é inegável o avanço das grandes corporações econômicas como centro de poder assumindo o controle do Estado e da sociedade, além do controle dos recursos naturais (Fenker \& Ferreira, 2011). Assim, estas questões geopolíticas coexistem com as fragilidades políticas e estruturais dos estados nacionais na definição de políticas, dificultando o cumprimento da política climática proposta por Giddens (2010).

Sob outra perspectiva, há um sólido consenso dos cientistas quanto ao impacto das emissões dos gases de efeito estufa na mudança climática. Para Graedel \& Crutzen (1997), o clima e o tempo são as

\footnotetext{
${ }^{5}$ Para Martinez Alier (2012) há uma transferência do dano ambiental para aqueles que compartilham seu modo de vida com a natureza atingindo a parte humana mais fraca deste sistema de exploração econômica
} 
mais óbvias manifestações de todos os processos do sistema terra, e as transformações recentes têm sido rápidas, nunca observáveis anteriormente na história. Marques Filho descreve 11 estudos científicos sobre projeções climáticas, realizados entre 2009 e 2015, por universidades e organismos científicos, para as próximas décadas e para 2100. Conclui que, sem a redução das emissões e o processo de descarbonização, será tarde para evitar o aumento superior a $2^{\circ} \mathrm{C}$ no horizonte de 2100 . Especificamente no Brasil, os relatórios apontam um aumento médio na temperatura de $3^{\circ}$ a $6^{\circ} \mathrm{C}$ em todas as regiões do país (Marques Filho, 2016).

Se a natureza e a fonte das alterações climáticas são evidenciadas cientificamente, o mesmo ocorre com as consequências em curso deste processo. A Organização das Nações Unidas criou em 1999 a organização Estratégia Internacional das Nações Unidas para a Redução de Desastres (United Nations Office for Disaster Risk Reduction-UNISDR) no sentido de agrupar sinergias com entidades e instituições com finalidade humanitária. Este órgão, juntamente com o Centre for Research on the Epidemiology of Disasters (CRED), publicou o The Human Cost of Weather-Related Disasters 1995-2015 (UNISDR \& CRED, 2015), relatando os desastres relacionados à mudança climática desde a Conferência sobre as Alterações Climáticas das Partes de 1995.

O relatório é uma análise dos dados compilados pelas instituições e está diretamente relacionado às mudanças climáticas no período especificado. Alguns relatos (UNISDR \& CRED, 2015): 90\% dos grandes desastres foram causados por 6.457 registros de inundações e enchentes, tempestades, secas, ondas de calor, frio extremo e incêndios florestais. Os eventos de inundações e tempestades correspondem a $71 \%$ dos desastres naturais em geral. De modo trágico, desde a COP-1, realizada em 1995, foram perdidas 606 mil vidas e 4,1 bilhões de pessoas ficaram feridas, desabrigadas ou precisaram de ajuda emergencial por eventos relacionados ao clima. A partir destes dados, pode-se inferir que ocorrem, em média anual, cerca de 30 mil mortes, e 205 milhões de pessoas são afetadas pelos desastres ambientais. As perdas econômicas relacionadas à mudança climática, em $71 \%$ dos eventos analisados, representam U\$ 1,9 trilhão.

$\mathrm{Na}$ introdução do relatório, Margareta Wahlström, da UNISDR, e Debarati Guha-Sapir, do CRED, destacam os riscos imediatos e mais amplos relacionados à alteração do clima:

\begin{abstract}
As mudanças climáticas, a variabilidade climática e os acontecimentos climáticos constituem uma ameaça à erradicação da pobreza extrema, e devem servir de estímulo para acelerar os esforços não somente para reduzir as emissões de gases de efeito de estufa, mas também para combater outros fatores de risco subjacentes, como desenvolvimento urbano não planejado, vulnerabilidade social, degradação ambiental e falhas nos alertas preventivos (UNISDR \& CRED, 2015, p. 3, tradução nossa).
\end{abstract}

Apesar da facticidade dos fenômenos e das suas consequências como acima apresentado, o que motiva as pessoas a questionarem ou negarem as evidências? Segundo Benestad et al. (2016), de 97\%

\footnotetext{
${ }^{6}$ Para os brasileiros, segundo Freitas (2019), os desastres ambientais como o de Mariana e Brumadinho são exemplos que extrapolam os danos e perdas de vidas imediatas e requerem o cuidado dos serviços públicos até a longo prazo.
} 
a $98 \%$ das publicações científicas atestam a origem antrópica do fenômeno do aquecimento global e confirmam as conclusões científicas aprovadas no IPCC-2007. O estudo revisou quase 12.000 resumos e recebeu 1.200 autoavaliações dos autores de publicações sobre ciência do clima. Qual seria o argumento dos 2 ou $3 \%$ remanescentes? De acordo com Benestad et al. (2016), foi realizado um estudo de revisão dos $2 \%$ das publicações que rejeitaram a origem antrópica do aquecimento global. Para isto, foi desenvolvido uma ferramenta analítica para replicar e testar os resultados e os métodos utilizados naqueles artigos. A conclusão revelou falhas metodológicas por se aterem a um caso específico e isolado, ignorando informações colaterais e a ampliação do campo de pesquisa. Apontou tambem o uso de falsas dicotomias e de modelos estatísticos inapropriados (Benestad et al., 2016).

As perpectivas negacionistas quanto à questão climática ficam evidenciadas e adquirem contornos particulares nos Estados Unidos da América, assumindo nítido caráter de debate ideológico. Para Jean-Daniel Collomb (2014, p.1, tradução nossa), "os negacionistas americanos da mudança climática têm sido notavelmente bem-sucedidos em confundir a opinião pública e retardar a ação decisiva". Relata o cientista que o movimento negacionista é organizado de forma complexa e, por duas décadas, desenvolveu um contínuo trabalho conjunto para desacreditar o consenso científico. Segundo
Collomb (2014), professor da Universidade de Lyon, o movimento americano é composto por três tendências: primeiro, o mais evidente, aqueles dos interesses socioeconômicos, com base nas indústrias de combustíveis fósseis. São poderosos interesses corporativos, como dos irmãos Koch ${ }^{7}$; segundo, dos que possuem forte compromisso ideológico conservador e se opõem a todas as formas de regulamentação e, terceiro, daqueles que defendem o modo de vida americano (American way of life) caracterizado pelo alto consumo.

Marques Filho analisa o fenômeno do negacionismo sob outra ótica, a partir dos mecanismos psicológicos que dificultam a tomada de consciência quanto à gravidade das crises ambientais. Aponta três mecanismos: o primeiro, "a forte preferência psicológica por evitar perdas, mais do que adquirir ganhos" (Marques Filho, 2016, p. 29). Este pensamento neutraliza a dissonância, gera paralisia por focar nas perdas imediatas e conduz à inação. Não nega a crise ambiental, por outro lado, não se mobiliza. O segundo mecanismo refere-se à habituação que consiste em "diminuição da resposta a um estímulo repetido, mas sem consequência imediata" (Marques Filho, 2016, p. 30). Este mecanismo impacta decrescentemente a consciência, havendo perda da noção de perigo que sempre reside no futuro. Reflete "um cansaço" frente aos frequentes e contínuos alertas ambientais. $O$ terceiro refere-se à dissociação "entre causas estruturais e

\footnotetext{
${ }^{7}$ De acordo com Costa (2016, p. 1), “A Koch Industries (dos irmãos Charles e David), a segunda maior empresa privada dos Estados Unidos é uma das 10 que mais poluem, detentora de refinarias de petróleo no Alaska, no Texas e em Minnesota, além de fábricas de celulose, tem muitos motivos para lutar contra a redução de emissões de gases estufa. Conforme revelado pelo documentarista Roben Greenwald, no filme "Koch Brothers Exposed", eles utilizam táticas intimidatórias, comprando veículos de comunicação, cientistas e políticos para que ideias contrárias ao debate sobre a vinculação das emissões de poluentes e o aquecimento global fossem propagadas. Esta corporação mantém uma ligação muito estreita com a ultradireita estadunidense e também financia o Partido Republicano, que resiste em aprovar medidas de corte de emissão no Congresso norte-americano, onde detém a maioria das cadeiras.".
} 
efeitos pontuais" (2016, p. 31). Demonstra sensibilidade ao evento, como um fato isolado que a mídia multiplica, sem relação causal e analítica temporal mais ampla.

Os três mecanismos, aversão à perda, habituação e dissociação conduzem a um quarto mecanismo, que é a "autonarrativa tranquilizante", caracterizada por Marques Filho (2016, p. 54) como "o autoengano" que consiste em "aceitar como verdadeira uma informação que desejamos que seja verdadeira". Não nega a evidência da crise ambiental, mas o afasta da consciência, e com isto afasta o colapso.

Partimos do problema de que a ação do homem produziu uma alteração biogeoquímica no planeta e a transformação da paisagem de modo brusco, em um curto período de tempo da história, originando uma crise civilizatória. Uma de suas manifestações, palpável na atualidade, reside nas consequências do aquecimento global e das mudanças climáticas. No ponto extremo desse arco, encontram-se os que assumem atitudes agressivamente negacionistas em relação a esses fenômenos e a seu caráter preponderantemente antropogênico, até mesmo deslocando o problema para o âmbito ontológico, como a matéria da revista The New York Times inicialmente abordada.

De posse destas problematizações, a pesquisa de opinião, objeto deste estudo, pretende identificar e compreender a percepção do brasileiro quanto à questão do aquecimento global, seu dimensiona- mento, causas e responsabilidade. São diferentes contextos, daquele da ciência e dos pesquisadores e daquele do país mais rico da terra. Em comum, o fato maior de habitarmos o mesmo planeta.

\section{A metodologia}

Os dados e resultados utilizados no presente estudo têm origem em fonte secundária. Trata-se de pesquisa de opinião pública publicada em maio de 2012, realizada pelo Instituto de Opinião Pública e Estatística, encomendada pela Confederação Nacional da Indústria (CNI \& IBOPE, 2012). O objetivo da pesquisa quantitativa era coletar informações sobre três temas relacionados ao meio ambiente: a preocupação com o meio ambiente, o aquecimento global e a mudança climática e a coleta seletiva de lixo e reciclagem. Cumpre ressaltar que é a última pesquisa publicada e disponível, em âmbito nacional, explorando de modo amplo as diversas variáveis dos temas do meio ambiente, da coleta seletiva e reciclagem, mudanças climáticas e aquecimento global a partir da perspectiva dos brasileiros. No entanto, utilizam-se as pesquisas mais recentes da Datafolha $^{8}$ (Garcia, 2019) e da Ipsos ${ }^{9}$ (Ipsos Global Adviser, 2019) para confrontar determinada variável na análise dos resultados.

Os dados do IBOPE foram coletados no período de 02 a 05 de dezembro de 2011, através de entrevistas pessoais, utilizando um questionário

\footnotetext{
${ }^{8}$ A pesquisa Datafolha, com margem de erro de 2\%, ouviu 2.086 pessoas em 130 municípios brasileiros em 04 e 05 de julho de 2019 , tendo como parâmetro a amostragem populacional do IBGE. A pesquisa indaga sobre a constatação do aquecimento global e sua origem, além da relação destes dados com as posições do atual governo federal.

${ }^{9}$ A pesquisa do Instituto Ipsos tem sua base em 27 países, coletando os dados online de 19.519 adultos, de 16 a 74 anos, no período de 22 de fevereiro a 22 de março de 2019. Informa o Instituto que os dados do Brasil e demais 11 países atingiram o público urbano e de maior nível educacional, portanto, não necessariamente representativo.
} 
(CNI \&IBOPE, 2012) e uma equipe treinada pelo instituto. O universo foi constituído por eleitores com idade de 16 anos ou mais. A pesquisa foi estratificada, cada estrato correspondendo a um Estado da federação. Os Estados do Acre, Amapá e Roraima compuseram um único estrato.

A amostragem da pesquisa (CNI \& IBOPE, 2012) utilizou um modelo com aglomerações em três estágios. O primeiro consistiu na seleção dos municípios através do método de "probabilidade proporcional ao tamanho" (PPT); o segundo consistiu na seleção dos conglomerados, dos setores censitários, também por meio do PPT sistemático, e o terceiro estágio selecionou em cada conglomerado um número fixo de pessoas segundo as variáveis amostrais.

A pesquisa foi realizada em 141 municípios brasileiros, envolvendo 2.002 entrevistas no território nacional. As fontes de dados para a elaboração da amostra são oriundas do "Censo 2000, PNAD 2008 e TSE 2010” (CNI \& IBOPE, 2012, p. 51).

A margem de erro máxima é estimada em dois pontos percentuais para mais ou para menos sobre os resultados, e o intervalo de confiança foi estimado em $95 \%$. Houve filtragem em todos os questionários após a realização das entrevistas através de "fiscalização em aproximadamente $20 \%$ dos questionários" (CNI \& IBOPE, 2012, p. 52).

Do conjunto da pesquisa foram utilizados, especificamente, os resultados e tabelas relativas ao tema do aquecimento global e mudanças climáticas ao qual se atém o presente estudo e que são objetos da análise. Especificamente, foram utilizados os dados gerais das questões relativas a: percepção do aumento da temperatura média da Terra nas últimas décadas, seriedade do aquecimento global, opinião dos brasileiros sobre as causas do aquecimento global, responsabilidade pelo aquecimento global e custos da adoção de tecnologias menos poluentes (CNI \& IBOPE, 2012).

\section{A mudança climática e a ação humana: o que pensam os brasileiros}

A principal constatação da pesquisa contratada pela Confederação Nacional da Indústria (CNI) é a de que a população brasileira está preocupada com o meio ambiente. O dado apurado aponta o percentual de $94 \%$ dos entrevistados. Destes, $64 \%$ manifestaram-se muito preocupados com as questões relacionadas ao meio ambiente (CNI \& IBOPE, 2012). Neste levantamento, por ordem de preocupação, o aquecimento global e a mudança climática compreendem $30 \%$ dos entrevistados, vindos atrás da questão do desmatamento da Amazônia, 53\%, e da poluição da água, que abrange $44 \%$ dos brasileiros.

Segundo Instituto Ipsos ${ }^{10}$ Ipsos Global Adviser, 2019), a questão do aquecimento global e da mudança climática preocupa $29 \%$ dos brasileiros, quarta posição quanto às preocupações ambientais. Esta questão ambiental, na pesquisa Ipsos, é antecedida pelo desmatamento, que é preocupação de $53 \%$ dos brasileiros, seguida pela poluição da água, para $44 \%$, e o tratamento do lixo, que atinge $36 \%$ dos entrevistados. No entanto, para a maioria dos 27 países pesquisados, o aquecimento global e mu-

\footnotetext{
${ }^{10}$ Em termos mundiais, segundo a pesquisa, a questão do aquecimento global e mudança climática situa-se em primeiro lugar, como problema ambiental, com 37\%, seguidos pela preocupação com poluição do ar, para 35\% e tratamento do lixo para 34\% dos entrevistados.
} 
dança climática é o assunto ambiental de maior preocupação, compreendendo $37 \%$ dos entrevistados.

Os resultados apresentados no presente estudo partem do objetivo de identificar a percepção, a identificação causal, dimensionamento e responsabilização da relação entre a ação humana e as mudanças climáticas, tema que conforme observamos acima confirma uma tendência de interesse e preocupação dos brasileiros no âmbito das questões dos problemas ambientais: $30 \%$ apurados na pesquisa de dezembro de 2011 (CNI \& IBOPE, 2012) e $29 \%$ no levantamento de junho de 2019 (Ipsos Global Adviser, 2019). Especificamente, em relação a todas as questões ambientais, aquelas relacionadas ao aquecimento global e à mudança climática constituem a preocupação de três entre cada dez brasileiros. Neste sentido, é importante indagar, a partir de uma pesquisa quantitativa, como o brasileiro percebe e pensa sobre esta problemática de nossos tempos.

A Figura 1 demonstra que $93 \%$ da população brasileira percebe o aumento de temperatura média do planeta nos últimos decênios. Somente 3\% afirmam taxativamente que a temperatura não está aumentando, percentual semelhante atesta não saber ou não quis responder. A pesquisa da Datafolha (Garcia, 2019) demonstra esta mesma tendência ao apontar que $85 \%$ da população brasileira reconhece que o planeta está se aquecendo.

Esta percepção do aumento de temperatura média nas últimas décadas é um elemento que consolida a preocupação de $94 \%$ dos brasileiros com as questões ambientais. No entanto, de acordo com Souza \& Corazza (2017), as mudanças climáticas se inscrevem no âmbito das questões denominadas "fronteiras planetárias" "11, que compreendem uma

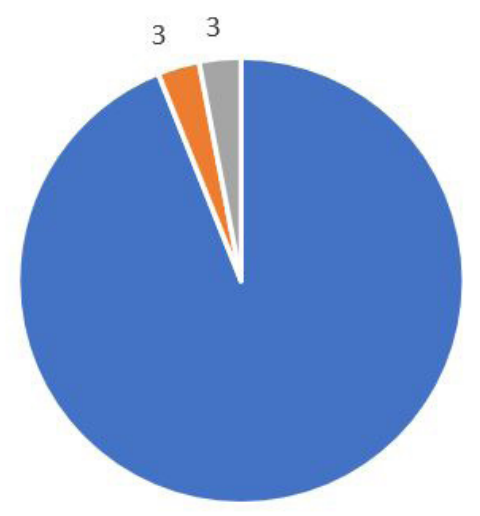

\author{
- Está aumentando \\ - Não está aumentando \\ - Não sabe/Não respondeu
}

93

FIGURA 1 - Percepção do aumento de temperatura média da Terra nas últimas décadas (percentual de respostas- \%).

FONTE: CNI \& IBOPE (2012, p.18). Elaboração própria.

\footnotetext{
${ }^{11}$ Um grupo de 29 cientistas (Rockström et al., 2009) propôs um conjunto de fronteiras biofísicas globais, denominadas "Fronteiras Planetárias", com base no entendimento científico do Sistema Terra com o objetivo de estabelecer um "espaço operacional seguro" que permita à humanidade avançar para gerações futuras. Das nove "fronteiras planetárias" identificadas (Steffen et al., 2015), há evidências de que três teriam sido ultrapassadas (mudanças climáticas, perda de biodiversidade e ciclo biogeoquímico de nitrogênio), causando já danos irreversíveis à Terra.
} 
visão sistêmica e complexa e, portanto, requerem uma aproximação científica e conceitual.

A percepção apurada e apontada na Figura 1 conteria o processo de verificação sob o rigor da ciência? Evidentemente que não. A aproximação por parte da população, à qual abrange o amplo espectro definido pela pesquisa IBOPE, origina-se no âmbito da necessidade, assim descrita por Alves (2002, p. 21): “o senso comum e a ciência são expressões da necessidade básica, a necessidade de compreender o mundo, a fim de viver melhor e sobreviver". Para Cotrim (2002, p. 46) o "vasto conjunto de concepções, geralmente aceitas como verdadeira em determinado meio social recebe o nome de senso comum" que nasce no cotidiano. As bases conceituais necessárias ao estudo científico e a pesquisa tem origem neste senso comum que são apropriados pelos métodos e tornam-se científicos ao romperem com o próprio senso comum e a visão do cotidiano (Alves, 2002; Cotrim, 2002). Mas como os fenômenos ambientais e, em particular, a questão do aquecimento global chegam até à pessoa comum?

Primeiro, pelo caminho da observação e pela prática cotidiana, motivada pela necessidade de explicar o mundo e as suas alterações que atingem a vida das comunidades. Em nova perspectiva epistemológica, Leff (2015) aborda a formação do saber ambiental, gerado num processo de conscientização e de pesquisa científica que busca sua fonte nas comunidades populares e tradicionais, suas práticas e técnicas culturais. Propõe ouvir aqueles que se situam no âmbito da externalidade socioeconômica e ambiental (Leff, 2015) e que constituem, em parte, a população atingida por desastres e catástrofes ambientais, ou ainda, pelos trabalhadores urbanos para os quais as consequências da degradação ambiental são mais do que meros incômodos casuais.

O segundo caminho é através dos meios de comunicação. Segundo Bueno (2017, p.27) as catástrofes e desastres ambientais despertam grande interesse na opinião pública e, portanto, há uma cobertura ampla da mídia tanto nacional como internacional:

\begin{abstract}
o tratamento jornalístico dispensado a estes eventos dramáticos incorpora as características gerais do jornalismo ambiental, oscilando quase sempre entre a espetacularização e a vigilância cívica, pela convergência de inúmeros fatores que condicionam ou constrangem o trabalho jornalístico.
\end{abstract}

Através do jornalismo, os brasileiros obtiveram conhecimento dos desastres e dos danos ambientais ocorridos no país. A jornalista Darly Gonçalves ${ }^{12}$ descreve os principais acontecimentos: 1980: Vale da Morte - toneladas de gases tóxicos foram despejados no ar do polo petroquímico de Cubatão (SP); 198: Vila Socó - uma falha em dutos subterrâneos da Petrobras espalhou 700 mil litros de gasolina nos arredores dessa vila, localizada também em Cubatão (SP); 1987: Césio 137- um grave caso de exposição ao material radioativo que ocorreu em Goiânia (GO); 2000: Vazamento de óleo na Baía de Guanabara - acidente com navio petroleiro resultou no derramamento de mais de um milhão de litros de óleo in natura no Rio de Janeiro; 2003: Vazamento de barragem em Cataguases - a barragem de celulose em Minas Gerais ocasionou

\footnotetext{
${ }^{12}$ A jornalista (Gonçalves, 2017) faz uma breve descrição dos principais desastres ambientais ocorridas no mundo e no Brasil a partir da segunda metade do século XX.
} 
o derramamento de mais de 500 mil metros cúbicos de rejeitos, compostos por resíduos orgânicos e soda cáustica; 2007: Rompimento de barragem em Miraí - causou o vazamento de mais de dois milhões de metros cúbicos de água e argila em Minas Gerais; 2011: Vazamento de óleo na Bacia de Campos- a empresa americana Chevron despejou no mar cerca de três mil barris de petróleo, provocando uma mancha de 160 quilômetros de extensão; 2015: Incêndio na Ultracargo- um incêndio no terminal portuário Alemoa, em Santos, ocasionando o lançamento de efluentes líquidos em manguezais e na lagoa contígua ao terminal; 2015: Rompimento da barragem de Mariana (MG) - em 5 de novembro de 2015, provocou a liberação de uma onda de lama de mais de dez metros de altura, contendo 60 milhões de metros cúbicos de rejeitos. Soma-se a estes desastres relatados o rompimento da barragem de Brumadinho, em 25 de janeiro de 2019, ocasionando a liberação de 11,7 milhões de metros cúbicos de rejeitos nos rios e ambientes vizinhos.

Segundo o relatório The Human Cost of Weather-Related Disasters 1995-2015 (UNISDR \& CRED, 2015), publicado pelas Nações Unidas, o Brasil está entre os 10 países do mundo com alto índice de pessoas afetadas, em números absolutos, por desastres ambientais relacionados à questão climática. Ao todo, calcula-se que 51 milhões de pessoas sofreram os efeitos de inundação, seca, tempestade e desmoronamento entre o ano de 1995 e 2015 . De acordo com o Ministério da Saúde (Brasil, 2018), entre o ano de 2000 e o primeiro semestre de 2017 foram registradas 6.164 situações de emergência oriundas de desastres hidrológicos, reconhecidas pelo Governo Federal, distribuídas em 51,6\% dos municípios brasileiros, ou seja, 2.872 localidades.

$\mathrm{O}$ número de pessoas impactadas, os fatos ocorridos no Brasil registrados acima, somados aos desastres ambientais ocorridos em outras partes do planeta, amplamente replicados pelos meios de comunicação, mesmo que de forma fragmentada e imprecisa ${ }^{13}$, contribuíram para maior percepção da problemática ambiental e, em especial, aquela relacionada ao aquecimento global e mudanças climáticas, assim como para o seu dimensionamento enquanto teor de gravidade, conforme verificada na Figura 2.

Ao se preocupar com o aquecimento global, o brasileiro considera o fenômeno como algo muito grave, para $65 \%$ dos entrevistados, ou ainda grave para 29\% (Figura 2). Somente 4\% dos brasileiros relaciona este fenômeno a algo de pouca gravidade ou nada grave. É relevante o fato de que $94 \%$ dos entrevistados considerem a seriedade do fenômeno do aquecimento global. É um reconhecimento de juízo, de valoração da gravidade do problema ambiental em questão e relacionado a sua compreensão das catástrofes e tragédias ambientais observadas ou vivenciadas.

Além dos acontecimentos ambientais catastróficos, a realização da Conferência das Nações Unidas sobre Desenvolvimento Sustentável no Rio

\footnotetext{
${ }^{13}$ Wilson Bueno (2017, p. 26), a partir do estudo de caso do rompimento da barragem de Mariana/MG, evidencia que o caráter mediático das catástrofes tem crescido nas últimas décadas. Relata que "no caso brasileiro, a inexistência de profissionais capacitados para esta cobertura em milhares de veículos distribuídos por todo o território nacional, o lobby poderoso desencadeado por interesses empresariais que impactam o meio ambiente (...), dentre outras razões, têm contribuído para uma cobertura fragmentada, descontextualizada e imprecisa da problemática ambiental.”. Ressalta, no entanto, a cobertura abrangente da mídia ambiental denunciando os abusos e desvios de governos e empresas, incorporando uma perspectiva crítica e comprometida com a causa da sustentabilidade.
} 
de Janeiro, em junho de 2012, as anuais Conferências das Partes e a celebração do Dia Mundial do Meio Ambiente proporcionam a exposição e divulgação, nas diversas mídias, do debate sobre a crise socioambiental, em especial àquelas relacionadas ao aquecimento global e à mudança climática.

Estas divulgações e aquelas relacionadas aos desastres ambientais, em grande parte originadas na ação humana, repercutem entre a população, deixam marcas significativas nos habitantes das regiões afetadas, bem como no meio ambiente, cuja recuperação pode levar décadas ou séculos. As imagens impactam de um modo crítico ou espetacularizado e permanecem no imaginário das pessoas. De acordo com Aguiar (2010), a supremacia da imagética visual na estruturação de extensas camadas de produção cultural é um sintoma de como a esfera do simbólico e do imaterial ocupam um lugar de grande relevância nas nossas sociedades.

Estas análises possibilitam compreender outros aspectos da pesquisa. Segundo o levantamento, o maior responsável pelo aquecimento global é a ação do ser humano, compreendido por $79 \%$ dos entrevistados (Figura 3). 16\% entendem que o fe-

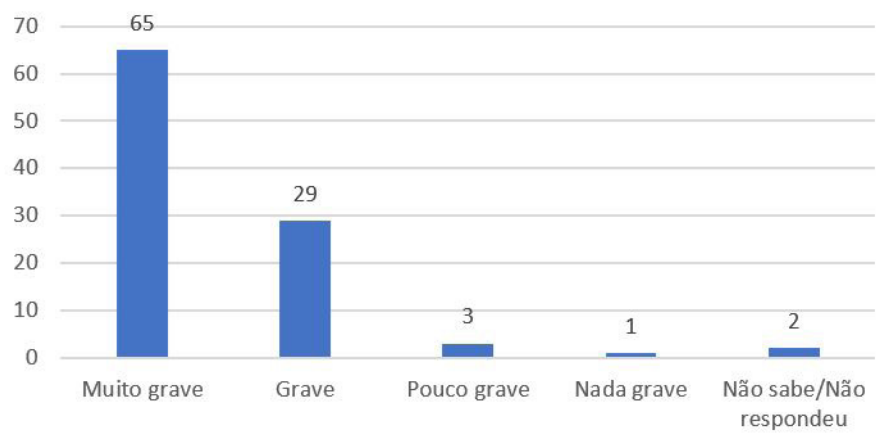

FIGURA 2 - Seriedade do aquecimento global (percentual de respostas - \%).

FONTE: CNI \& IBOPE (2012, p. 19). Elaboração própria.

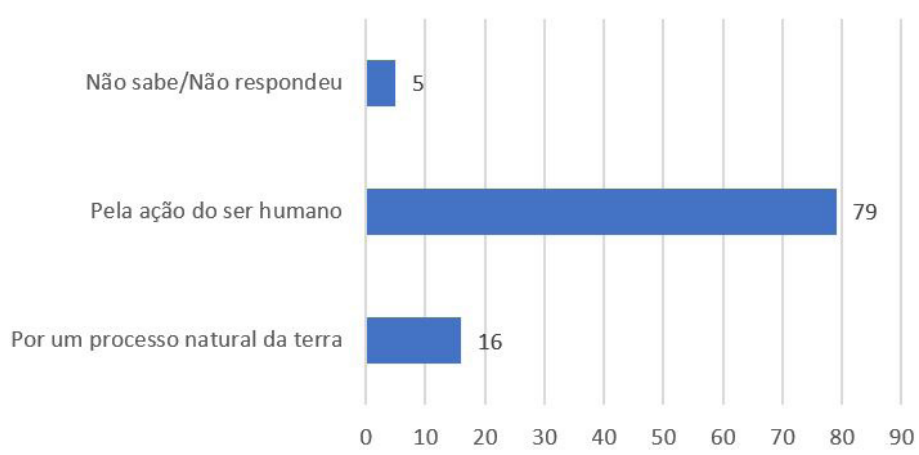

FIGURA 3 - Causas do aquecimento global (percentual de respostas- \%).

FONTE: CNI \& IBOPE (2012, p. 21). Elaboração própria. 
nômeno é um processo natural da Terra, e 5\% não se pronunciaram. Próxima a esta tendência, $72 \%$ dos pesquisados pela Datafolha (Garcia, 2019) acreditam que o aquecimento tem origem antropogênica, conduzindo o periódico a concluir que a maioria da população está alinhada com os elementos centrais do consenso científico sobre o tema.

Toda e qualquer atividade humana causa um impacto ambiental, não somente na paisagem, mas no ecossistema local e, proporcionalmente, no planeta. A percepção da alteração global do clima e do aquecimento, o reconhecimento da seriedade deste fenômeno e a proposição da causa antrópica dessas mudanças é uma informação relevante, pois este dado deve refletir nos projetos de educação ambiental, como também na elaboração e implementação das políticas públicas.

Para a ciência, como foi exposto na segunda seção deste artigo, a determinação das origens e processo destas mudanças ambientais envolve um conhecimento complexo e sistêmico, por meio de diversas áreas do conhecimento que permitem advogar a inter e a transdisciplinariedade na identificação das fontes, da causalidade e das consequências dos fenômenos. Ao tratar da questão da causalidade, Souza \& Corazza afirmam que a problemática ambiental e, em particular as mudanças climáticas, exigem a compreensão científica do fenômeno

(...) com causalidades que não podem ser admitidas como unidirecionais, apresentando ciclos de retroalimentação; (...) há um sensível interregno temporal entre a instalação das causas e as observações dos efeitos, o que coloca a dimensão intertemporal como central nos causa-efeito (Souza \& Corazza, 2017, p. 53).
Sob outra perspectiva, a cobertura da problemática ambiental e a comunicação com a população através da mídia, incluso a questão da causalidade, é realizada de forma fragmentada, descontextualizada e imprecisa (Bueno, 2017). De acordo com Aguiar (2010), a construção da imagem na reportagem obedece aos princípios diferentes da investigação científica, não focaliza a perspectiva de totalidade, não oferece uma explicação do seu objeto quanto a sua contextualização social e histórica. Como consequência, assegura:

(...) a repetição de reportagens imageticamente semelhantes sobre o mesmo tema e com o mesmo ângulo de perspectivação reforça ainda mais um sentimento de "inevitabilidade" desses fenômenos. Aqui, a banalização da visão de tais reportagens pode, em termos probabilísticos, caminhar de par em par com uma crescente insensibilidade em relação ao tema (Aguiar, 2010, p. 192).

Esta última perspectiva é também corroborada por Marques Filho (2016), ao traçar os mecanismos psicológicos que impedem a tomada de consciência da gravidade das crises ambientais e abordada no capítulo segundo: a aversão à perda, a habituação, ou seja, a repetição de reportagens e consequente banalização e, por fim, a dissociação entre causas estruturais e efeitos pontuais explorados pela mídia.

A Figura 3, no entanto, apresenta um quadro majoritário de entendimento da origem antrópica sobre as causas do aquecimento global. Mesmo a abordagem superficial e fragmentada da mídia não tem alterado esta percepção na pesquisa. Somente $16 \%$ dos entrevistados entenderam ser um processo natural da terra, aos quais poderiam se incluir nos mecanismos mencionados anteriormente. Portanto, não há evidências de constituírem um movimento 
"negacionista" como o existente nos Estados Unidos da América, como expressão de ideologias conservadoras e interesses econômicos capitalistas (Collomb, 2014).

O conhecimento científico e o conhecimento comum não necessitam estar dissociados ou relacionados, pois mesmo a pesquisa tem início no conhecimento vulgar (Alves, 2002). Por outro lado, o senso comum não passa necessariamente pelo critério de verdade ou falsidade, mas sim pela falta de fundamentação teórica e experimentação, são processos acríticos e relacionados ao cotidiano humano (Cotrim, 2002). Origina-se, portanto, na experiência do cotidiano e a partir da necessidade de explicar a sua realidade, como a experiência do morador das cidades contemporâneas ao perceber a desconstrução e construção, tanto no aspecto físico como social, operados no processo da expansão urbana. Segundo Ueda et al., (2018), estas atividades humanas têm impacto sobre o espaço e sobre a paisagem ${ }^{14}$. São experiências cotidianas que elaboram uma maneira de compreender o mundo, as alterações nele provocadas e a origem antrópica deste processo.

A identificação da causa do aquecimento global está vinculada em consequência à indicação da responsabilidade pelo mesmo fenômeno, cujo resultado da pesquisa pode ser verificado na Figura 4.

Os entrevistados ficaram divididos quanto à identificação dos principais responsáveis (Figura 4). Atribuem parcela maior às indústrias $38 \%$. Em seguida, a pesquisa apurou que $22 \%$ dos entrevistados atribuem a responsabilidade pelo aquecimento climático aos cidadãos, e 18\%, aos governos. Cum-

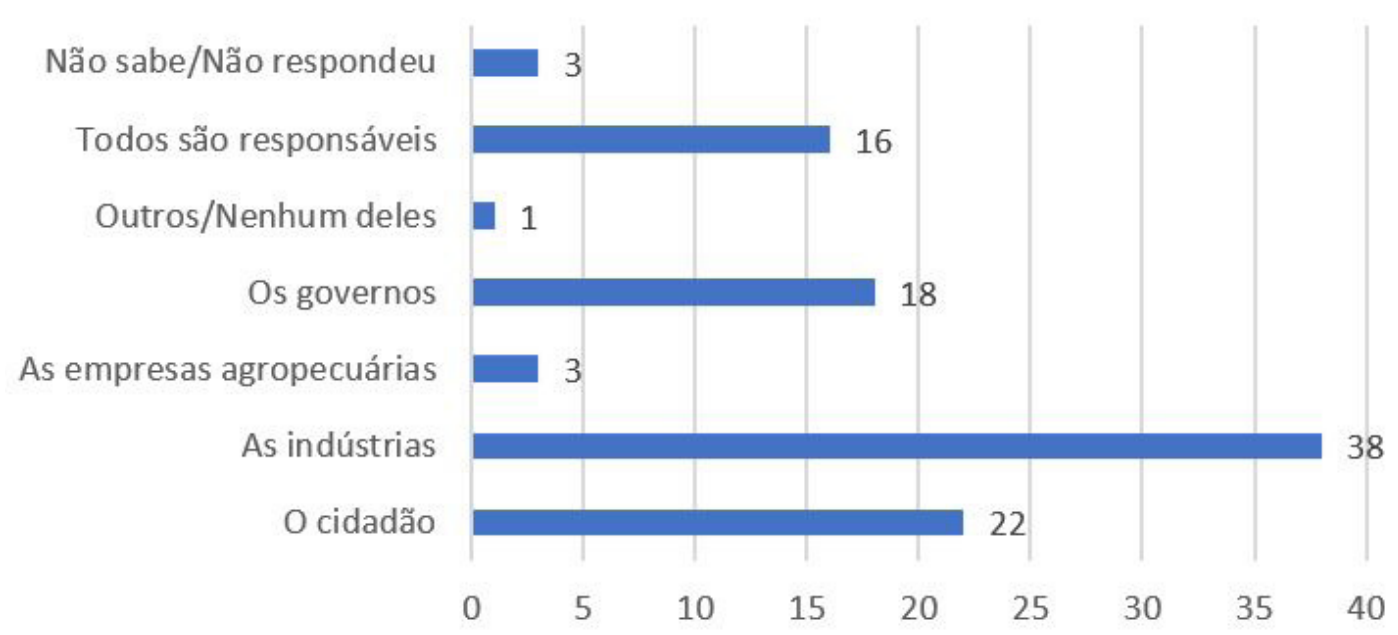

FIGURA 4 - Responsabilidade pelo aquecimento global (percentual de respostas- \%).

FONTE: CNI \& IBOPE (2012, p. 22). Elaboração própria.

${ }^{14}$ Os autores analisam o processo de desconstrução física e social nas cidades brasileiras a partir de um recorte histórico. 
pre observar que somente $3 \%$ dos entrevistados atribuíram responsabilidade às empresas do setor agropecuário, sediadas nos ecossistemas brasileiros onde ocorreram grandes transformações nas últimas décadas. $16 \%$ responderam que todos são responsáveis. Não há um consenso de responsabilização específica, exceção ao papel maior atribuído ao setor industrial.

As pesquisadoras Souza \& Corazza entendem que a atribuição de responsabilidade quanto à questão ambiental e, especificamente, aquelas relacionadas às mudanças climáticas é um difícil processo, visto que tem sua origem em fontes múltiplas e difusas, e acrescentam: "suas consequências são cumulativas e se desdobram para além das fronteiras nacionais" (2017, p. 53).

O painel científico criado pela ONU em 1988, o IPCC, tem produzido relatórios sistemáticos que resumem extensas pesquisas científicas diretamente relacionadas ao aquecimento global e à mudança climática. De acordo com Marques Filho (2016), em 1995, o relatório do IPCC apontava uma probabilidade maior que $50 \%$ quanto à origem de tais fenômenos serem causados por atividades humanas. Este percentual subiu para 95\% no relatório de 2013.

A busca de responsabilidade compartilhada e diferenciada, do ponto de vista histórico, diante do fenômeno em pauta, e a necessidade de redução de emissões dos gases de efeito estufa são os grandes embates e o propósito das Conferências Mundiais sobre as questões ambientais e climáticas a partir da última década do século XX. Segundo Souza \& Corazza, este movimento, principalmente a partir das anuais Conferências das Partes, tem provocado mudanças substantivas nas lideranças, nas coalizões entre os países e na atribuição de responsabilidades que compreendem como uma "reconfiguração da arquitetura do regime climático" (2017, p. 76).

Quanto à responsabilidade atribuída na pesquisa, entende-se que não se trata de uma responsabilização causal quanto ao fenômeno ambiental, como também não constitui uma leitura das estimativas das emissões antrópicas produzidas ${ }^{15}$ no país ou no mundo ${ }^{16}$, mas sim uma responsabilização política e prática no sentido de orientar a busca de soluções através de ações concretas ${ }^{17}$. Neste sentido, há um destaque para responsabilização do setor industrial e, em seguida, salienta a participação da ação do cidadão, do governo e do conjunto da sociedade. Por outro ângulo de análise, há uma visão de compartilhamento da responsabilidade entre os diversos segmentos da sociedade.

\footnotetext{
${ }^{15}$ Desde 1958, no observatório de Mauna Loa no Havaí vem sendo estudado e medido a curva de Keeling, que calcula a concentração de CO2 na atmosfera em partículas por milhão (ppm). No Brasil o último relatório refere-se ao ano de 2015, publicado em 2017. A participação nas emissões líquidas por setor para os anos de 2015, em percentual, corresponde: $5 \%$ relacionados ao tratamento de resíduo, $7 \%$ aos processos industriais, $24 \%$ a mudança de uso da terra e floresta, 31\% vinculado a agropecuária e 33\% relacionados à produção e uso da energia (BRASIL, 2017).

${ }^{16}$ A concentração de CO2 na atmosfera atingiu novo recorde no mês de maio de 2019, com 414,65 partes por milhão (ppm), segundo dados da National Oceanic \& Atmospheric Administration (NOAA, 2019).

${ }^{17}$ Os dados das estimativas anuais de emissões não estão disponíveis no Ministério do Meio Ambiente. Relacionados ou não a este fato, segundo o jornal O Estado de São Paulo (Borges, 2019), a redução das ações do governo brasileiro contra o aquecimento global chega a 96\% devido ao corte no orçamento do ano de 2019.
} 


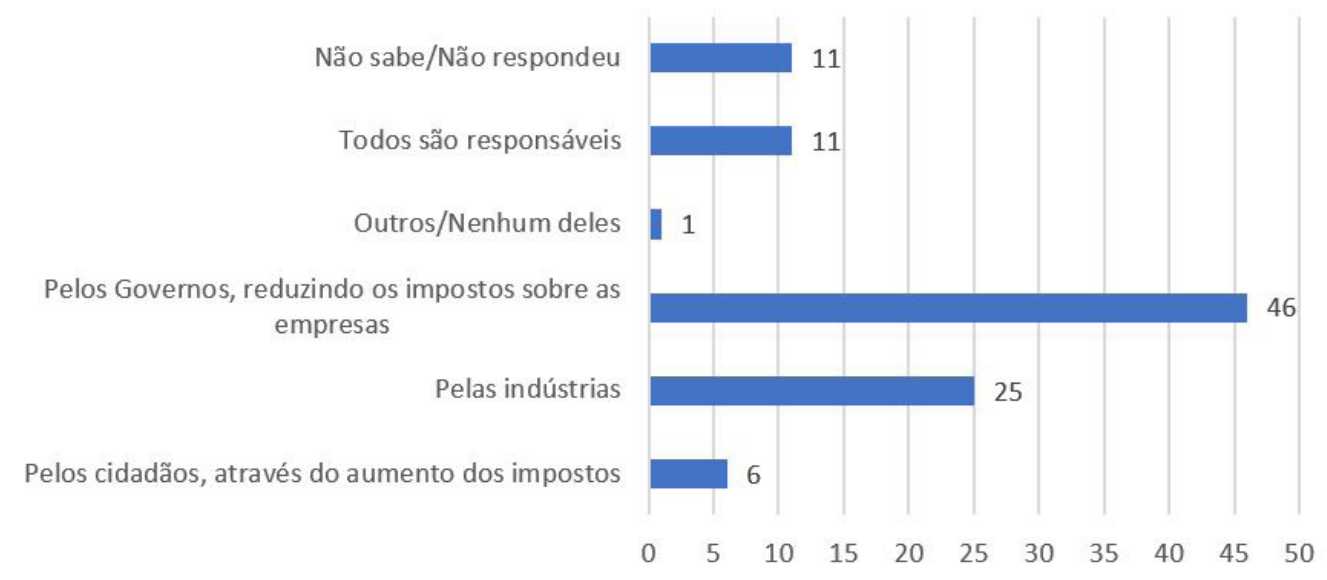

FIGURA 5 - Custos da adoção de tecnologias menos poluentes (percentual de respostas- \%).

FONTE: CNI \& IBOPE (2012, p. 23). Elaboração própria.

A Figura 5 está relacionada aos custos, ou seja, ao ônus da redução das emissões de carbono. A quem caberia?

$11 \%$ dos entrevistados não souberam ou não responderam, o mesmo percentual acreditou que todos, cidadão, governo e indústria, devem ser responsáveis. Segundo $6 \%$ dos pesquisados, os cidadãos apenas devem arcar com este custo através do aumento dos impostos. Um quarto dos entrevistados atribuiu às indústrias a responsabilidade pelo custo de adoção de tecnologias limpas. $\mathrm{Na}$ pesquisa, entretanto, quase metade da população brasileira, ou seja, $46 \%$ dos entrevistados, apontam que os custos da redução das emissões devem ser assumidos pelos governos.

Há nestes dados uma desconexão com a figura anterior, entre a determinação de quem teria responsabilidade pelo fenômeno do aquecimento global (Figura 4) e, agora, a indicação do setor ou segmento social que deveria arcar com os custos da tecnologia para reduzir poluentes (Figura 5). Este fator torna-se evidente nas indicações relacionadas ao setor industrial e governo. O primeiro é responsável pelo aquecimento global para 38\% dos entrevistados, mas somente $25 \%$ acreditam que devem, eles próprios, arcarem com os custos da solução, ou seja, a adoção de tecnologia menos poluente. Na Figura 4, os governos são responsáveis pelo fenômeno ambiental para $18 \%$ da amostra da pesquisa; no entanto, para $46 \%$ dos entrevistados são responsáveis para arcar com os custos tecnológicos, visando a solução do problema ambiental como evidenciado na Figura 5. Esta posição descreve ainda o mecanismo para arcar com as despesas:

\footnotetext{
${ }^{18}$ Em uma pesquisa quantitativa, o dado é construído (Lima, 2016, p. 13), pois “a construção de um problema de pesquisa é feita pela identificação de determinados aspectos da realidade social que serão submetidas a uma observação.”. Para o autor, a pesquisa sempre lida com viés, uma distorção, que normalmente é equacionada com a margem de erro. No entanto, considera importante estar atento ao modo como se produz o estímulo e os elementos de possíveis respostas (Lima, 2016).
} 
redução dos impostos sobre as empresas, entendidas anteriormente como o principal responsável para quase metade dos entrevistados ${ }^{18}$.

Esta última questão coloca ainda um pressuposto de solução: a tecnologia. O pensamento conservador funda-se na crença de que a tecnologia, somada aos mecanismos de mercado, constitui a solução para as externalidades ambientais (Collomb, 2014; Leff, 2015). Marques Filho (2016, p. 637) entende esta crença como uma tentação da engenharia, a "pretensão à administração técnico-científica dos desequilíbrios ecológicos antropogênicos".

Após analisar os mecanismos psicológicos que impedem a tomada de consciência da gravidade e origem das crises ambientais, objetivo, em tese, oposto ao pretendido na referida pesquisa de opinião, Marques Filho (2016, p.32) afirma que:

(...) o mais importante fator a reforçar nosso bloqueio cognitivo seja a crença de que o Estado é ainda capaz de nos "salvar" ou ao menos de assumir sua parcela maior de responsabilidade na condução de políticas susceptíveis de reverter a degradação em curso na biosfera.

Esta concepção ignora a aliança do Estado com a economia capitalista. Esta economia age de forma independente, não prioriza o meio ambiente e funda-se na crença do crescimento e progresso contínuo e ilimitado (Georgescu-Roegen, 2012). Ignora a aliança do Estado com as corporações multinacionais como centro de poder e controladores inclusive dos recursos naturais (Fenker \& Ferreira, 2011), que justificam a hipótese de uma nova fase do Capitalismo de Estado, ou seja, do Estado-Corporação entendido como uma relação de continuidade entres estes âmbitos (Marques Filho, 2016). Neste sentido, o Estado atual e seus agentes políticos não têm o poder e interesse de intervir na questão da preservação ambiental e mesmo ser uma força dissonante na questão da produção e do consumo.

A partir dos dados analisados, evidencia-se uma homogeneidade na percepção do aquecimento global e da mudança climática como um problema (93\%) e, ademais, há um entendimento majoritário quanto à predominância da ação humana (79\%) na origem e causa do fenômeno ambiental. Esta percepção vem acompanhada por um entendimento amplo $(94 \%)$ quanto à gravidade e seriedade do problema. Os entrevistados atribuem a responsabilidade por estes fenômenos aos vários setores e segmentos da sociedade, no entanto, não consolidam esta visão na determinação de proporcional responsabilização quanto aos custos da adoção de tecnologias menos poluentes.

Se, por um lado, existe a constatação do problema a partir da identificação dos seus efeitos na atual realidade, por outro lado, evidencia-se que há uma insegurança quanto ao futuro, ou seja, o fenômeno é algo que afeta e poderá afetar a vida futura. Estas percepções fazem parte da preocupação do brasileiro. Entretanto, por tratar-se de uma pesquisa de opinião pública, não é possível analisar o sentido e significado desta consciência e a sua predisposição à ação emancipatória da natureza e do homem.

Deste modo, se por um lado, a partir dos dados, é impossível deduzir que há um estágio de conscientização que vincule a percepção do aquecimento global ao questionamento do modo de produção e de consumo da sociedade capitalista, por outro lado, observa-se também, fora do âmbito direto da pesquisa, que não há um fator e movimento mobilizador da sociedade civil diante do quadro alarmante da crise ambiental. Seria esta inação um dos sintomas 
da "autonarrativa tranquilizante" de que nos alerta Marques Filho (2016, p. 54)?

\section{Considerações finais}

Os dados da pesquisa de opinião pública dos brasileiros, realizada pelo CNI-IBOPE, evidenciam duas questões relevantes: a primeira, na constatação de que existe uma percepção de modo significativo e preponderante do problema do aquecimento global e da mudança climática e, a segunda, de que há a compreensão de que o problema ambiental em pauta tem origem na ação humana. Questões estas confirmadas pela pesquisa da Datafolha de 2019.

As Conferências Internacionais sobre o meio ambiente e as pesquisas científicas têm sido, em termos de conhecimento, o ponto de mutação para a exigência de uma mudança estrutural da sociedade a partir da ação humana sobre o ambiente. Os meios de comunicação exercem influência ambivalente, entretanto, são instrumentos essenciais no desenvolvimento da consciência individual e histórica. Somente a sociedade organizada e consciente será capaz de advogar e pôr em prática um novo paradigma de produção e consumo harmônicos com o meio ambiente e o planeta.

O Antropoceno, mais do que a designação de uma época geológica, manifesta os sinais de esgotamento de um modo de vida, de produção e consumo. Os sintomas da crise ambiental manifestos na mudança climática, de um lado e, por outro, o sistema econômico pautado pela lógica da exclusão social e gerador de desigualdades, são duas faces de uma mesma moeda. Neste sentido, o Antropoceno é também o sinal de esgotamento de um modo de pensar. A crise provocada pelo aquecimento global está relacionada ao paradigma cientificista, cuja ideia de progresso coloca o ser humano em colisão com a Terra. Está relacionada à visão reducionista da Terra, a qual deve ser manipulada e controlada, ou ainda, à visão antropocentrista que coloca o homem como centro e acima da natureza e do universo.

A superação destas formas de pensar compreende a passagem da percepção à consciência transformadora. Esta exigirá uma formulação mais exata do problema ambiental, suas causas, responsabilidades, e exigirão soluções estruturantes e significativas. O humano, colocado como o ponto de mutação do planeta, pode também ser um ponto de transformação para uma nova Terra.

A percepção do brasileiro evidenciada na pesquisa revela uma disposição de receptividade para aprofundar a compreensão do fenômeno do aquecimento global. Abre perspectivas para debates e para o processo educacional capazes de orientar os sujeitos para uma ação emancipatória. As evidências aqui analisadas abrem também espaço para futuras pesquisas no âmbito da subjetividade, proporcionando aos organismos responsáveis a formulação correta dos problemas e as soluções necessárias para que esta percepção antrópica não se transforme em forma de insegurança constante, ou mesmo, em habituação e anestesia proporcionados pelos discursos tranquilizantes. Se por um lado, não existe uma posição cética e negacionista entre os brasileiros, por outro lado, não existem ações sistemáticas para a expansão da consciência, seja no nível do cotidiano como no âmbito cultural e político. O processo de consciência está sendo substituído por reações imediatistas e simplificadoras do real. Espaços abertos para o debate, para a teoria e a prática. 


\section{Referências}

Aguiar, J. V. A imagem na cultura do pós-modernismo. Tempo Social, 22(1), 179-198, 2010. Disponível em: www.scielo.br/scielo.php?script=sci_arttext\&pi$\mathrm{d}=\mathrm{S} 0103-20702010000100009 \& \operatorname{lng}=\mathrm{pt} \& \mathrm{nrm}=$ iso

Aguiar, P. K. Perspectiva da Transição para Economia de Baixo Carbono a partir da Cooperação Internacional pós-Kyoto. In: Peralta, C. E.; Leite, J. R. M.; Mello, M. E. (Orgs.). Temas da Rio+20: desafios e perspectivas. Florianópolis: Fundação Boiteaux, p. 12-40, 2012.

Alves, R. Filosofia da ciência: introdução ao jogo e suas regras. São Paulo: Loyola, 4. ed., 2002.

Barbieri, J. C. Desenvolvimento e meio ambiente: as estratégias de mudanças da Agenda 21. Petrópolis: Vozes, 9. ${ }^{\mathrm{a}}$ ed., 2008.

Bauman, Z. Vida líquida. Rio de Janeiro: Zahar, 2. ed., 2009.

Benestad, R. E.; Nuccitelli, D.; Lewandowsky, S.; Hayhoe, K.; Hygen, H. O.; Dorland, R. van.; Cook, J. Learning from mistakes in climate research. Theoretical and Applied Climatology, 126, 699-703, 2016. doi: 10.1007/s00704015-1597-5

Boff, L. Sustentabilidade: o que é: o que não é. Petrópolis: Vozes, 4. ed., 2015.

Boff, L. El encuentro feliz de la Pachamama con Gaia, Servicios Koinonía, 2017. Disponível em: <http://www. servicioskoinonia.org/boff/articulo.php?num $=840 \geq$. Acesso em: ago. 2018.

Borges, A. Ministério do Meio Ambiente quase zera verba de combate à mudança climática. O Estado de São Paulo, 2019. Disponível em: <https://sustentabilidade.estadao.com.br/ noticias/geral,ministerio-do-meio-ambiente-quase-zera-verba-de-combate-a-mudanca-climatica,70002818539>. Acesso em: mai. 2019.

Brasil. Ministério da Ciência, Tecnologia, Inovações e Comunicações. Estimativas anuais de emissões de gases de efeito estufa no Brasil. 4. ed., 2017. Disponível em: $<$ file:///F:/Downloads/P2L00001\%20(1).pdf $>$. Acesso em: jun. 2019

Brasil. Ministério da Saúde. Secretaria de Vigilância em Saúde. Boletim Epidemiológico 10 (49), 2018. Disponível em: $<$ http://portalarquivos2.saude.gov.br/images/pdf/2018/ marco/22/2017-032-Publicacao.pdf>. Acesso em: jun. 2019.

Bueno, W. C. A cobertura jornalística de catástrofes ambientais: entre a vigilância e a espetacularização da notícia. Comunicação \& Sociedade, 39(1), 21-41, 2017.

Collomb, J. D. The Ideology of Climate Change Denial in the United States. European jornal of American studies, 9(1), 1-20, 2014. Available on: ejas.revues.org/10305

Costa, H. S. Mudanças climáticas versus interesses privados. EcoDebate [online], 2016. Disponível em: $<$ https://www. ecodebate.com.br/2016/01/08/mudancas-climaticas-versus-interesses-privados-artigo-de-heitor-scalambrini-costa/>. Acesso em: mai. 2019.

CNI - Confederação Nacional da Industria; IBOPE - Instituto Brasileiro de Opinião Pública e Estatística. Retratos da sociedade brasileira: meio ambiente. Brasília: Confederação Nacional da Indústria, 2012. Disponível em: $<$ http://arquivos.portaldaindustria.com.br/app/conteudo_2 4/2012/07/09/80/20120828024710449864e.pdf >. Acesso em: abr. 2018.

Cotrim, G. Fundamentos da filosofia: história e grandes temas. São Paulo: Saraiva, 15. ed., 2002.

Crutzen, P. J.; Stoermer, E. The "Anthropocene". IGBP Newsletter, 41, 17-18, 2000. Available on: www.igbp.net/downlo $\mathrm{ad} / 18.316 \mathrm{f} 18321323470177580001401 / 1376383088452 /$ NL41.pdf

Crutzen, P. J. Geology of mankind. Nature, 415(23), 2002. doi: $10.1038 / 415023 a$

Fenker, E. A.; Ferreira, E. Sustentabilidade: Economia e Ecologia Sustentáveis? In: Anais do XXXV Encontro da ANPAD. Rio de Janeiro, 4-7 de set., 2011.

Freitas, C. M. de; Barcellos, C.; Asmus, C. I. R. F.; Silva, M. A. da; Xavier, D. R. Da Samarco em Mariana à Vale em Brumadinho: desastres em barragens de mineração e Saúde Coletiva. Cadernos de Saúde Pública, 35(5), 2019. 
doi: 10.1590/0102-311x00052519

Garcia, R. No Brasil, 85\% afirmam que o planeta está se aquecendo. Folha de São Paulo, 2019. Disponível em: $<$ https://www1.folha.uol.com.br/ambiente/2019/07/no-brasil-89-afirmam-que-o-planeta-esta-se-aquecendo.shtml $>$. Acesso em: maio 2020.

Georgescu-Roegen, N. O decrescimento: entropia, ecologia, economia. São Paulo: Senac São Paulo, 2012.

Giddens, A. A política da mudança climática. Rio de Janeiro: Zahar, 2010.

Gonçalves, D. P. Principais desastres ambientais no Brasil e no mundo. Jornal da Unicamp [online], 2017. Disponível em: <https://www.unicamp.br/unicamp/ju/ noticias/2017/12/01/principais-desastres-ambientais-no-brasil-e-no-mundo>. Acesso em: out. 2018.

Graedel, T. E.; Crutzen, P. J. Atmosphere, climate, and change. New York: Scientific American Library, 1997.

Habermas, J. Conhecimento e Interesse. Rio de Janeiro: Ed. Guanabara, 1987.

IPCC - Intergovernmental Panel on Climate Change. IPCC First Session Report. Geneve, 1988. Available on: <http:// www.ipcc.ch/meetings/session01/first-final-report.pdf>. Acess on: May 2020.

IPCC - Intergovernmental Panel on Climate Change. Climate Change 2007: Synthesis Report, 2007. Avalilable on: <http://www.ipcc.ch/scripts/_session_template. php?page=_27ipcc.htm $\geq$. Acess on: May 2020 .

IPCC - Intergovernmental Panel on Climate Change. IPCC Fourty-Seventh Session Report, 2018. Available on: $<\mathrm{http}: / /$ www.ipcc.ch/meetings/session47/final_report_p47.pdf $>$. Acess on: May 2020

IPEA - Instituto de Pesquisa Econômica Aplicada. Sustentabilidade Ambiental no Brasil: biodiversidade, economia e bem-estar humano. Brasília: Ipea, 2010.

Ipsos Global Advisor. Earth Day 2019: how does the world perceive our changing environment? 2019. Disponível em: <https:/www.ipsos.com/sites/default/files/ct/news/ documents/2019-05/g_earth_day_2019.pdf $>$. Acesso em: jun. 2019.
Leff, E. Saber ambiental: sustentabilidade, racionalidade, complexidade, poder. Petrópolis: Vozes, 11. ed., 2015.

Lima, M. Introdução aos métodos quantitativos em Ciências Sociais. In: Alonso, A; Miranda, D. S. de. Métodos de pesquisa em ciências sociais: bloco quantitativo. São Paulo: Sesc São Paulo/CEBRAP, 2016. p. 10-31.

Marques Filho, L. C. Capitalismo e colapso ambiental. Campinas: Editora da Unicamp, 2. ed., 2016.

Martinez Alier, J. O ecologismo dos pobres: conflitos ambientais e linguagens de valoração. São Paulo: Contexto, 2. ed., 2012.

Morin, E. Introdução ao pensamento complexo. Porto Alegre: Sulina, 4. ed., 2011.

NOAA - National Oceanic \& Atmospheric Administration. Global Monitoring Laboratory. Trends in Atmospheric Carbon Dioxide. 2019. Available on: <www.esrl.noaa.gov/ gmd/ccgg/trends/>. Acess on: Jun. 2019.

Normile, D. Key climate panel, citing impending crisis, urges crash effort to reduce emissions. Science Magazine, 2018. doi:10.1126/science.aav6720

Portella Filho, P. O ajustamento na América Latina: crítica ao modelo de Washington. Lua Nova, 32, 101-132, 1994. doi: 10.1590/S0102-64451994000100007

Rich, N. Losing earth: the decade we almost stopped climate change. The New York Times Magazine, 2018. Available on: <https://www.nytimes.com/interactive/2018/08/01/ magazine/climate-change-losing-earth.html $>$. Acess on: Sept. 2018.

Rockström, J.; Steffen, W.; Noone, K.; Persson, Â.; Chapin, F. S. III.; Lambin, E.; Lenton, T. M.; Scheffer, M.; Folke, C.; Schellnhuber, H. J.; Nykvist, B.; Wit, C. A. de; Hughes, T.; Leeuw, S. van der; Rodhe, H.; Sörlin, S.; Snyder, P. K.; Costanza, R.; Svedin, U.; Falkenmark, M.; Karlberg, L.; Corell, R. W.; Fabry, V. J.; Hansen, J.; Walker, B.; Liverman, D.; Richardson, K.; Crutzen, P.; Foley, J. Planetary boundaries: exploring the safe operating space for humanity. Ecology and Society, 14(2), 2009. Available: https://www. ecologyandsociety.org/vol14/iss2/art32/

Sachs, I. Desenvolvimento: includente, sustentável, sustentado. Rio de Janeiro: Garamond, 2008. 
Santos, B. de S. Para um novo senso comum: a ciência, o direito e a política na transição paradigmática. São Paulo: Cortez, 3. ed., 2001.

Seligman-Silva, M. A técnica na sofisticada marcha da humanidade em direção ao precipício. 2019. Disponível em: $<$ https://www1.folha.uol.com.br/ilustrissima/2019/02/a-tecnica-na-sofisticada-marcha-da-humanidade-em-direcao-ao-precipicio.shtml>. Acesso em: abr. 2019.

Souza, M. C. O.; Corazza, R. I. Do Protocolo de Kyoto ao Acordo de Paris: uma análise das mudanças no regime climático global a partir do estudo da evolução de perfis de emissões de gases de efeito estufa. Desenvolvimento $e$ Direito, 42, 52-80, 2017.

SQS - Subcommission on Quaternary Stratigraphy. Working Group on Antropocene, 2009. Available on: $<$ http://quaternary.stratigraphy.org/working-groups/anthropocene/ $\geq$. Acess on: May 2020.

Steffen, W.; Richardson, K.; Rockström, J.; Cornell, S. E.; Fetzer, I.; Bennett, E. M.; Biggs, R.; Carpenter, S. R.; Vries, W. de; Wit, C. A. de; Folke, C.; Gerten, D.; Heinke, J.; Mace, G. m.; Persson, L. M.; Ramanathan, V.; Reyers, B.; Sörlin, S. Planetary boundaries: Guiding human development on a changing planet. Science Magazine, 2015. Available on: $<$ https://science.sciencemag.org/content/347/6223/1259855/ tab-pdf>. Acess on: May 2020.
Ueda, G. S.; Francisco, J.; Castro, C. M. P. O papel do capital na desconstrução do espaço social. Arquitetura Revista, 14(1), 73-82, 2018.

UNISDR - United Nations Office for Disaster Risk Reduction; CRED - Centre For Research on the Epidemiology of Disasters. The Human Cost of Weather-Related Disasters 1995-2015. Brussels; Geneve: CRED; EM-DAT; UNISDR, 2015. Available on: <https://www.preventionweb.net/ files/46796_cop21weatherdisastersreport2015.pdf > . Acess on: Nov. 2018.

Veiga, J. E. Desenvolvimento Sustentável: o desafio do século XXI. Rio de Janeiro: Garamond, 2010.

Veiga. J. E. O Antropoceno e a ciência do sistema Terra. São Paulo: Editora 34, 2019. 